INT'L. J. PSYCHIATRY IN MEDICINE, Vol. 31(1) 97-109, 2001

\title{
RELIGION AND MEDICINE II: RELIGION, MENTAL HEALTH, AND RELATED BEHAVIORS
}

HAROLD G. KOENIG, M.D.

Duke University Medical Center, and

GRECC, Veterans Administration Medical Center

Durham, North Carolina

\begin{abstract}
In this second in a series of articles on religion and medicine, I focus on the relationship between religion and mental health. This discussion is based on a comprehensive and systematic review of a century of research examining religion's relationship to mental health, social support, substance abuse, and other behaviors affecting mental or social functioning. This review includes over 630 separate data-based reports that focus on religion and well-being, hope and optimism, meaning and purpose, depression, suicide, anxiety, psychosis, social support and marital stability, alcohol and drug abuse, cigarette smoking, extra-marital sexual behaviors, and delinquency. Reasons for the associations found are discussed and conclusions drawn in light of the findings.
\end{abstract}

(Int'l. J. Psychiatry in Medicine 2001;31:97-109)

Key Words: religion, spirituality, psychology, social support, addiction

In the first article of this series, I examined how religion may adversely affect mental health in a number of ways [1]. Religious abuses of the mentally ill during the Renaissance period resulted in hundreds of persons being persecuted as witches or demon-possessed and executed by the Inquisition [2]. Not only have well-respected mental health professionals expressed concerns about the neurotic 
or emotionally destabilizing influences of religion [3, 4], but a number of research studies also report associations between religious involvement and psychiatric illnesses like schizophrenia and depression $[5,6]$.

On the other hand, even Freud [7] noted that religion could provide a worldview that gives meaning to life: ". . . only religion can answer the question of the purpose of life. One can hardly be wrong in concluding that the idea of life having a purpose stands and falls with the religious system." Furthermore, in a letter to Oskar Pfister [8] and again in an address to the Vienna Psychoanalytic Society [9], he even remarked that religious faith may help to stifle neuroses. Freud saw religion as one of the most convenient and comfortable methods for sublimating the instinctual drives, going so far as to suggest that there had been an "extraordinary increase in neuroses since the power of religions has waned" [10]. Thus, even in the mind of one of religion's greatest critics, there was a realization that religious faith might have mental health benefits for some persons.

In order to address this question of whether religion has negative or positive effects on mental health, let us turn to research on that subject. Three decades ago, a comprehensive review of research on religion and mental health published in the American Journal of Psychiatry by Victor Sanua, a professor in the Department of Social and Psychological Foundations at the City University of New York, seemed to answer that question:

The contention that religion as an institution has been instrumental in fostering general well-being, creativity, honesty, liberalism, and other qualities is not supported by empirical data. Both Scott (55) and Godin (22) point out that there are no scientific studies which show that religion is capable of serving mental health [11].

My colleagues and I have recently completed a comprehensive and systematic review of research on religion and mental health during the 20th century [12]. This was accomplished by employing a combination of three strategies. First, we performed computer searches of the literature (Medline, Current Contents, Psychlit, Soclit, HealthStar, Cancerlit, CINAHL, and others) to identify quantitative studies that had examined the religion-mental health relationship. Second, since the computer searches went back only as far as the middle 1960 s, we consulted the footnotes and references of articles retrieved by the search to identify other relevant studies. After retrieving these studies, the process was repeated again until no new studies could be found. Third, in order to identify studies not located by the previous two methods, we reviewed articles and books that examined the topic. Proceeding in this manner, over 630 reports were discovered.

Many of the studies finding a negative relationship between religion and mental health were reviewed in the first article of this series [1]. Studies reporting a positive relationship, however, far outnumber those finding either no association or a negative relationship. Because of limited space, I summarize the main findings of the review, providing details only on exemplary studies or studies 
whose results deviate from the norm. More information about investigations not discussed here may be found in the original review [12].

\section{PSYCHOLOGICAL WELL-BEING}

Religious beliefs and practices are consistently related to greater life satisfaction, happiness, positive affect, morale, and other indicators of well being. Of the 100 studies located that examined this association, nearly 80 percent $(n=79)$ reported only significant positive correlations between these constructs. Of the ten cohort studies that employed a prospective analysis of associations, nine reported that religious characteristics at baseline predicted greater well-being over time. While the correlations reported by many studies were modest, they often equaled or exceeded those between well-being and other psychosocial variables like marital status, income, and social support. Of the 100 studies, 13 found no association between religious involvement and well-being, seven reported mixed or complex relationships, and one study found only a significant negative relationship [13]. The latter investigation was a cross-sectional survey involving two small student samples $(n=109$ and $n=96)$ that did not control for covariates, and the only consistent finding in the two populations was a correlation between poor mental health and two of eight religious measures - ritualism and superstition.

\section{HOPE AND OPTIMISM}

Of the 15 studies examining a relationship between religiousness and hope or optimism, 12 reported significant positive associations and two found no association. No studies found that religious persons were less optimistic than the nonreligious. The three studies with the best methodologies (in terms of sampling method and study design) all found positive relationships [14-18].

\section{PURPOSE AND MEANING}

Sixteen studies that examined the relationship between religious involvement and purpose or meaning were found. Of those studies, 15 reported a significant positive association and one found no association. The only study not finding an association was Burbank's [19] cross-sectional survey of 57 older participants in a senior center program in Rhode Island. A single open-ended question assessed meaning: "Is there something or things so important to you in your life that they give your life meaning?" Respondents listed 60 items that gave life meaning; the most common were relationships (73 percent) and religion (13 percent). When these categories were correlated with fulfillment of meaning (assessed using a standardized 12-item scale), subjects in the religion category did not score differently on meaning than other groups. Even in this study, however, religion was an important source of meaning for a number of participants. 


\title{
DEPRESSION
}

A total of 101 studies were located that examined the relationship between level of religious involvement and depression, including eight clinical trials. Of 93 observational studies, 59 reported only lower rates of depressive disorder or fewer depressive symptoms among those with greater religious involvement. Of the remaining 33 studies, 13 reported no association, four reported only greater depression among the more religious [5, 20-22], and 16 studies reported mixed findings (significant positive correlations with some religious variables and significant negative correlations with others).

Of the 22 prospective cohort studies, 15 found that greater religious involvement at baseline predicted lower rates of depression on follow-up. Two studies identified depressed subjects and followed them over time; in both of these studies, depression resolved quicker among subjects who were more religious $[23,24]$. Of the eight clinical trials, five showed that depressed patients receiving religious interventions recovered faster than subjects receiving only a secular intervention or those in control groups [25-29]. Studies examining religiousness and suicide were also reviewed. Of 68 studies that examined suicide rates or attitudes by level of religious involvement, 57 found less suicide or more negative attitudes toward suicide among the more religious. Of the remaining 11 studies, nine showed no relationship and two reported mixed results.

\begin{abstract}
ANXIETY
A total of 76 studies were located which examined the religion-anxiety relationship: seven clinical trials and 69 observational studies. Of the observational studies, 35 found only lower levels of anxiety or less fear among the more religious, 17 reported no association, seven reported mixed or complex results, and 10 reported greater anxiety among the more religious. Of the latter 10 studies finding greater anxiety, two examined religious affiliation only, three examined prayer or religious coping in cross-sectional analyses (where anxious persons may have turned to prayer or religion because of their anxiety), and three studies were conducted among clinical populations (HIV-positive patients and psychiatric patients) or religiously unstable persons (those who had suddenly converted to a different religious faith). More important, of the seven clinical trials, six reported significant benefit in terms of anxiety relief from religious interventions. In summary, the majority of the studies found less anxiety and fear among the more religious, including four of five prospective cohort studies [30-33] and six of seven clinical trials [29, 34-38].
\end{abstract}

\section{PSYCHOTIC SYMPTOMS AND DISORDERS}

At least 16 studies have examined the relationship of religion to psychotic symptoms or disorders. Of these studies, 13 measured religiousness and three 
examined differences across religious denominations. Among the studies examining religiousness, one was a prospective cohort study and two were clinical trials. Of the remaining 10 cross-sectional studies, four found fewer psychotic tendencies, symptoms, or disorders among the more religious, three found no association, two reported mixed findings, and one found a positive relationship between religion and psychotic disorder. The latter study, as discussed in the first paper of this series, found that religious beliefs, practices, and experiences were more common among 73 depressed or schizophrenic psychiatric inpatients in a London hospital compared to 26 control patients from the orthopedic service [5]. The only prospective study to examine the relationship between religion and psychotic disorder involved a two-year follow-up of 386 schizophrenic patients treated in outpatient clinics in Madras and Vellore, India [39]. Patients who reported a decrease in religious activities at the baseline evaluation had significantly poorer outcomes $(p<.001)$.

The three denominational studies each examined different religious groups. In a study conducted in New York City, Jews were found to have more depression, Catholics more personality and adjustment disorders, and Protestants more schizophrenia [40]. In a study from Australia, Jehovah Witnesses were more likely to have schizophrenia than other members of the Australian population [41]. A third study from Israel reported that compared to Jews or Catholics, Bahai and Hari Krishna were more likely to have a history of psychotic episodes requiring hospitalization [42].

The remaining two studies involved clinical trials where a religious intervention was utilized as a treatment modality among patients with chronic psychoses. The first study administered a psycho-educational program to help patients (two-thirds with schizophrenia) utilize spiritual beliefs to foster healthy self-esteem [43]. No changes in either depressive symptoms or self-esteem were observed following the intervention. The second study involved 20 schizophrenic patients receiving student nurse interventions that involved weekly prayer and scripture reading [44]. Subjects demonstrated notable improvements in several aspects of mental functioning following the intervention, although no statistical comparisons were made. In neither study above did religious interventions cause worsening of the psychotic illness. With the exception of one study, it appears that religious involvement (particularly within mainstream religious groups) is either unrelated or negatively related to psychosis.

\section{SOCIAL SUPPORT}

Of 20 studies located that quantitatively assessed the relationship between religious involvement and social support, 19 found only statistically significant positive associations between an indicator of religious involvement and social support. Five of these studies involved random samples of community-dwelling adults that ranged in size from 2956 to 4522 subjects [45-49]. 
In the only non-significant study, Walls and Zarit [50] examined the friendship networks of 98 older subjects recruited from African-American churches in urban areas of Pennsylvania. Investigators found that 50 percent indicated their closest friends were family members and 40 percent indicated their closest friends were members of their church. Not surprisingly, family members were significantly more likely than church members to provide emotional and functional support. Nevertheless, church members still provided a lot of support for these aging African Americans. Church-related social support appears to be particularly important for older adults, regardless of race. In a study of 106 predominantly Caucasian geriatric patients attending a family medicine clinic in Springfield, Illinois, the majority indicated their closest friends were church members (52 percent indicated that 80 percent or more of their closest friends came from their churches) [51].

With regard to marital support, 35 of 38 studies found greater marital happiness or stability among the more religious or those with similar religious backgrounds (denominational homogamy). One study found no association between marital stability and denominational homogamy, and the remaining two studies reported mixed results - both examining domestic abuse. Included among the positive reports was Strawbridge and colleagues' 28-year study of 5,286 participants in the Alameda County Study in California, which found that persons who attended religious services at least once weekly were 80 percent more likely than others to stay married during the follow-up period [52].

\section{SUBSTANCE USE}

\section{Alcohol Use/Abuse}

At least 95 studies have quantitatively examined the religion-alcohol relationship (including nine studies comparing denominations). Of the 86 studies that have examined level of religiousness, 76 (88 percent) reported significantly less alcohol use/abuse among religious subjects (including eight of nine prospective cohort studies). Note that 40 of the 76 studies finding less alcohol use/abuse among the religious involved adolescents or college students. Of the 10 studies that did not find an inverse relationship with alcohol use/abuse, six studies found no association, two reported mixed results, and two found only positive relationships between alcohol use/abuse and religion [53, 54]. With regard to the latter two studies, Waisberg and Porter [53] conducted a clinical trial that examined two interventions for alcoholism: Treatment $\mathrm{A}$, a multi-modal approach that included a spiritual component, and Treatment $\mathrm{B}$, an approach that was entirely spiritual. Subjects receiving Treatment A had better outcomes than those receiving Treatment B. Subjects in each treatment group, however, were not equally matched; patients receiving Treatment A were older, had higher incomes, and were less likely to have legal problems. 
In the second study, Zucker and associates [54] followed 61 male alcoholics from an inpatient alcohol treatment program in the Bronx, New York. Method of assessing religiosity was not specified, but was reported to be correlated with religious attendance. Religious patients had more anti-alcohol attitudes on admission, but when changes in attitudes toward alcohol were examined four weeks later, those who were least religious experienced greater changes toward anti-alcohol attitudes. The least religious patients, however, started from a lower baseline and had greater room for change in attitude. Furthermore, religious patients had more prior admissions for detoxification and rehabilitation, so were probably a more treatment resistant group. Finally, persons with strong religious attitudes who continue to drink excessively are probably a rather select group of individuals.

\section{Drug Use}

Religiousness is also associated with less recreational drug use, again especially in younger persons. At least 56 studies have quantitatively tested this relationship. Of those studies, 52 examined the relationship between religiousness and drug use (four compared drug use among members of different religious groups). As with alcohol use/abuse, most studies (48 out of 52) found less drug use among the more religious; two studies reported no association, one study reported mixed results, and one study greater drug use. The latter was a cross-sectional survey of 90 undergraduates and 58 health professionals at University of Nevada in Reno, which found that the variable "personal spiritual experiences" (experience of God, belief in God, sense of spiritual awakening, prayer to God) was positively related to greater drug use $(r=.32, p<.001)$, a correlation the investigators found "puzzling" [55]. Forty-two of 48 studies that found a relationship between greater religiousness and lower drug use involved samples of adolescents or college students.

\section{Cigarette Smoking}

Of the 25 studies that quantitatively examined the relationship between religiousness and smoking, 24 (96 percent) reported less smoking among the more religious. Of the 24 studies that found an inverse relationship between religion and smoking, 12 were in adolescents or college students. This relationship between cigarette smoking and religious involvement during adolescence and young adulthood is particularly important because it is during these early years that the habit of cigarette smoking typically begins. In their study of almost 4000 older adults, Koenig and colleagues [56] found that the reason why religiously active subjects smoked less than non-religious subjects was because the former were less likely to ever start smoking (rather than being more likely to quit). Thus, if religiousness can help prevent the onset of cigarette smoking in youth, then the health benefits of avoiding this habit may accumulate over a lifetime. Nearly 21 percent of coronary 
heart disease deaths, 30 percent of cancer deaths, and almost all deaths from chronic bronchitis and emphysema could be prevented if Americans never started to smoke [57].

\section{OTHER BEHAVIORS}

In this section, I examine other behaviors affecting mental and social functioning that religious beliefs and practices might be expected to influence.

\section{Extra-Marital Sexual Activity}

Most studies suggest that religious involvement is inversely related to premarital and extra-marital sexual attitudes and activity, number of sexual partners, high-risk sexual practices, and likelihood of developing a sexually transmitted disease. Of the 38 quantitative studies located, 37 (97 percent) found that the religious had significantly lower rates or more negative attitudes toward nonmarital sex than non-religious subjects. The vast majority of these studies $(n=32)$ were again conducted in adolescents or college students.

\section{Delinquency and Crime}

Of 36 studies that examined the relationship between religious involvement and delinquency or crime, 28 (78 percent) found significantly lower rates of these activities among the more religious. Of the other eight studies, six found no association, one reported mixed results, and one found a positive relationship between religion and delinquency. In one of the largest and best-designed studies on the topic, Stark [58] analyzed data on religion and delinquency from a national random sample of 11,995 high school seniors. He found that students who attended religious services more regularly were significantly less likely to get into trouble with the law, a finding that held true for all areas of the country except the Pacific Northwest. Other studies involving random samples of 12,000-21,000 high school students have reported similar findings [59, 60].

Most recently, Wallace and Forman [61] analyzed data on religious involvement, delinquency, substance use, and health behaviors in a random sample of 5000 students from 135 high schools across the United States as part of University of Michigan's Monitoring the Future Project. Unintentional and intentional injury behaviors (carrying a weapon to school, engaging in interpersonal violence, low seat belt use, drinking while driving, riding while drinking), substance use (cigarette smoking, binge drinking, marijuana use), and lifestyle factors (diet, exercise, and sleep) were examined. Importance of religion was inversely related to carrying a weapon to school, interpersonal violence, driving while drinking, riding while drinking, and low seat belt use, as was cigarette smoking, binge drinking, and marijuana use. 
Frequency of religious attendance was even more strongly related to less substance use and fewer intentional and unintentional injury behaviors. In addition, students who indicated that religion was very important to them or who frequently attended religious services were significantly more likely to engage in regular exercise, eat healthy, and have more regular sleep patterns. The findings remained significant after adjusting for multiple demographic variables, and appeared to persist over time based on time-trend analyses.

\section{REASONS FOR THE ASSOCIATION}

Why is religious involvement often associated with improved coping, less emotional disorder, greater social support, greater marital stability, less substance abuse, and fewer behaviors that adversely affect human relationships and health? First, religious belief provides a positive worldview that gives experienceswhether positive or negative-meaning. Meaning, in turn, provides a sense of purpose and direction in life, and a more hopeful and optimistic attitude. Difficult circumstances - adjustment problems in youth, financial difficulties, loss of loved ones, impaired health, and functional disability - are appraised in a more positive light when seen from a religious worldview, compared to a viewpoint that sees these events and circumstances as resulting from random chance or bad luck. Furthermore, many religions portray the universe as personal and friendly, with order and direction that benefits humans and, perhaps, was created for humans. The alternative worldview sees humans as simply chance happenings in a vast, cold, merciless, threatening universe.

Second, religious beliefs and practices may evoke positive emotions-joy, wonder or awe, thankfulness - during deep states of meditation, prayer, or communal worship. These positive emotions may counteract or provide relief from the stresses of daily life, and provide alternative sources of pleasure that rival habits and activities destructive to self or human relationships.

Third, religion provides rituals that ease and sanctify major life transitionsadolescence, marriage, and death-rallying those in the community to support each other through such changes. Religious beliefs also prescribe support and care for others, encouraging character traits such as altruism, kindness, generosity, forgiveness, and love for neighbor - even in circumstances where the neighbor cannot return such favors. These behaviors, in turn, promote harmony within communities and build "social capital." Religious beliefs and practices also promote family and marital bonds and facilitate the building of extended social networks of non-family ties that can provide both emotional and physical assistance in time of need.

Fourth, as an agent of social control, religious beliefs provide guidance on and structure for the kinds of behaviors that are acceptable and conform to social norms. Most religions have proscriptions against excessive alcohol use, drug use, extra-marital sexual activity, delinquency, lying, cheating, and other behaviors 
that negatively affect the person or their social environment. Among the religious, such proscriptions tend to be reinforced by family and peer groups. When followed, such proscriptions often lead to better decision-making and reduce the likelihood of negative life events that create stress and unhappiness.

\section{CONCLUSIONS}

I summarize here the results of a systematic review of research examining the relationship between religion and mental health over the past century. The vast majority of studies that have examined relationships between religion, mental health, social support, and other behaviors linked with mental health and social functioning, report positive connections. This is not to say that all religions or any single religion always promotes positive human emotions, satisfying relationships, or healthy lifestyles. As noted in the first paper of this series, religion can be used to induce guilt, shame, and fear or justify anger and aggression. It can promote social isolation, particularly for those failing to conform to religious standards. As an agent of social control, religion may be over-restrictive and limiting. In general, however, most mainline religions with well-established traditions and accountable leadership tend to promote positive rather than negative human experiences.

\section{REFERENCES}

1. Koenig HG. Religion and medicine I: Historical background and reasons for separation. International Journal of Psychiatry in Medicine 2000;30:385-398.

2. Zilboorg G. A History of Medical Psychology. New York: WW Norton Co., 1941.

3. Freud S. Future of an Illusion (1927). In: Strachey J, editor and translator. Standard Edition of the Complete Psychological Works of Sigmund Freud. London: Hogarth Press, 1962.

4. Ellis A. Psychotherapy and atheistic values: A response to A. E. Bergin's "Psychotherapy and religious values." Journal of Consulting and Clinical Psychology 1980; 48:635-639.

5. Neeleman J, Lewis G. Religious identity and comfort beliefs in three groups of psychiatric patients and a group of medical controls. International Journal of Social Psychiatry 1994;40(2):124-134.

6. Strawbridge WJ, Shema SJ, Cohen RD, Roberts RE, Kaplan GA. Religiosity buffers effects of some stressors on depression but exacerbates others. Journal of Gerontology 1998;53:S118-S126.

7. Freud S. Civilization and its discontents (1930). In: Strachey J, editor and translator. Standard edition of the complete psychological works of Sigmund Freud. London: Hogarth Press, 1962:25.

8. Freud S. In: Meng H, Freud EL, editors. Psychoanalysis and faith: The letters of Sigmund Freud \& OsKar Pfister (1909). New York: Basic Books, 1963:16.

9. Freud S. In: Nunberg H, Feden E, editors. Minutes of the Vienna psychoanalytic society, vol 2: 1908-1910. New York: International Universities Press, 1967:149. 
10. Freud S. The future prospects of psychoanalytic therapy (address made to the Second Psycho-Analytical Congress) (1910). In: Strachey J, editor and translator. Standard edition of the complete psychological works of Sigmund Freud, vol 11. London: Hogarth Press, 1962:146.

11. Sanua VD. Religion, mental health, and personality: A review of empirical studies. American Journal of Psychiatry 1969;125:1203-1213.

12. Koenig HG, McCullough M, Larson DB. Religion and health: A century of research reviewed. New York: Oxford University Press, 2001.

13. Maranell GM. Religiosity and personality adjustment. In: Maranell GM, editor. Responses to religion. Lawrence: The University Press of Kansas, 1974.

14. Sethi S, Seligman MEP. Optimism and fundamentalism. Psychological Science 1993; 4:256-259.

15. Sethi S, Seligman MEP. The hope of fundamentalists. Psychological Science 1994; 5:58.

16. Idler EL, Kasl SV. Religion among disabled and nondisabled elderly persons: Crosssectional patterns in health practices, social activities, and well-being. Journal of Gerontology 1997;52B:S300-S305.

17. Ringdal G, Gotestam K, Kaasa S, Kvinnslaud S, Ringdal K. Prognostic factors and survival in a heterogeneous sample of cancer patients. British Journal of Cancer 1995;73:1594-1599.

18. Ringdal G. Religiosity, quality of life and survival in cancer patients. Social Indicators Research 1996;38:193-211.

19. Burbank PM. An exploratory study: Assessing the meaning in life among older adult clients. Journal of Gerontological Nursing 1992;18:19-28.

20. Schafer WE. Religiosity, spirituality, and personal distress among college students. Journal of College Student Development 1997;38:633-644.

21. Sorenson AM, Grindstaff CF, Turner RJ. Religious involvement among unmarried adolescent mothers: A source of emotional support? Sociology of Religion 1995; 56:71-81

22. Spiegel D, Bloom JR, Gottheil E. Family environment as a predictor of adjustment to metastatic breast carcinoma. Journal of Psychosocial Oncology 1983;1:33-44.

23. Braam AW, Beekman ATF, Deeg DJH, Smith JH, van Tilburg W. Religiosity as a protective or prognostic factor of depression in later life: Results from the community survey in the Netherlands. Acta Psychiatrica Scandinavica 1997;96:199-205.

24. Koenig HG, George LK, Peterson BL. Religiosity and remission from depression in medically ill older patients. American Journal of Psychiatry 1998;155:536-542.

25. Azhar MZ, Varma SL. Religious psychotherapy in depressive patients. Psychotherapy \& Psychosomatics 1995;63:165-173.

26. Propst LR. The comparative efficacy of religious and nonreligious imagery for the treatment of mild depression in religious individuals. Cognitive Therapy \& Research 1980;4:167-178.

27. Propst LR, Ostrom R, Watkins P, Dean T, Mashburn D. Comparative efficacy of religious and nonreligious cognitive-behavior therapy for the treatment of clinical depression in religious individuals. Journal of Consulting \& Clinical Psychology 1992;60:94-103.

28. Toh YM, Tan SY. The effectiveness of church-based lay counselors: A controlled outcome study. Journal of Psychology \& Christianity 1997;16:260-267. 
29. Razali SM, Hasanah CI, Aminah K, Subramaniam M. Religious-Sociocultural psychotherapy in patients with anxiety and depression. Australian \& New Zealand Journal of Psychiatry 1998;32:867-872.

30. Cooley CE, Hutton JB. Adolescent response to religious appeal as related to IPAT anxiety. Journal of Social Psychology 1965;56:325-327.

31. Morris PA. The effect of pilgrimage on anxiety, depression and religious attitude. Psychological Medicine 1982;12:291-294.

32. Paloutzian RF. Purpose in life and value changes following conversion. Journal of Personal \& Social Psychology 1981;41:1153-1160.

33. Williams DR, Larson DB, Buckler RE, Heckmann RC, Pyle CM. Religion and psychological distress in a community sample. Social Science and Medicine 1991; 32:1257-1262.

34. Azhar MZ, Varma SL, Dharap AS. Religious psychotherapy in anxiety disorder patients. Acta Psychiatrica Scandinavica 1994;90:1-3.

35. Carlson CR, Bacaseta PE, Simanton DA. A controlled evaluation of devotional meditation and progressive relaxation. Journal of Psychology \& Theology 1988; $16: 362-368$.

36. Kabat-Zinn J, Massion AO, Kristeller J, Peterson LG, Fletcher KE, Pbert L, Lenderking WR, Santorelli SF. Effectiveness of a meditation-based stress reduction program in the treatment of anxiety disorders. American Journal of Psychiatry 1992; 149:936-943.

37. Miller JJ, Fletcher K, Kabat-Zinn J. Three-year follow-up and clinical implications of mindfulness meditation-based stress reduction intervention in the treatment of anxiety disorders. General Hospital Psychiatry 1995;17:192-200.

38. Xiao S, Young D, Zhang H. Taoistic cognitive psychotherapy for neurotic patients: A preliminary clinical trial. Psychiatry \& Clinical Neurosciences 1998;52(supplement): S238-241.

39. Verghese A, John JK, Rajkumar S, Richard J, Sethi BB, Trivedi JK. Factors associated with the course and outcome of schizophrenia in India: Results of a two-year multicentre follow-up study. British Journal of Psychiatry 1989;154: 499-503.

40. Flics DH, Herron WG. Activity-withdrawal, diagnosis, and demographics as predictors of premorbid adjustment. Journal of Clinical Psychology 1991;47:189-196.

41. Spencer J. The mental health of Jehovah's Witnesses. British Journal of Psychiatry 1975;126:556-559.

42. Ullman C. Psychological well-being among converts in traditional and nontraditional religious groups. Psychiatry 1988;51:312-322.

43. Lindgren KN, Coursey RD. Spirituality and serious mental illness: A two-part study. Psychosocial Rehabilitation Journal 1995;18(3):93-111.

44. Carson V, Huss K. Prayer: An effective therapeutic and teaching tool. Journal of Psychiatric Nursing \& Mental Health Services 1979;17:34-37.

45. Bradley DE. Religious involvement and social resources: Evidence from the data set, “Americans' Changing Lives." Journal for the Scientific Study of Religion 1995;34:259-267.

46. Ellison CG, George LK. Religious involvement, social ties, and social support in a southeastern community. Journal for the Scientific Study of Religion 1994; 33:46-61. 
47. Idler EL, Kasl SV. Religion among disabled and nondisabled elderly persons: Crosssectional patterns in health practices, social activities, and well-being. Journal of Gerontology 1997;52B:S300-S305.

48. Koenig HG, Hays JC, George LK, Blazer DG, Larson DB, Landerman LR. Modeling the cross-sectional relationships between religion, physical health, social support, and depressive symptoms. American Journal of Geriatric Psychiatry 1997;5:131-143.

49. Ortega ST, Crutchfield RD, Rushing WA. Race differences in elderly personal well-being. Research on Aging 1983;5:101-118.

50. Walls CT, Zarit SH. Informal support from black churches and the well-being of elderly blacks. Gerontologist 1991;31:490-495.

51. Koenig HG, Moberg DO, Kvale JN. Religious activities and attitudes of older adults in a geriatric assessment clinic. Journal of the American Geriatric Society 1988;36: 362-374.

52. Strawbridge WJ, Cohen RD, Shema SJ, Kaplan GA. Frequent attendance at religious services and mortality over 28 years. American Journal of Psychiatric Hospitals, 1997;87:957-961.

53. Waisberg JL, Porter JE. Purpose in life and outcome of treatment for alcohol dependence. British Journal of Clinical Psychology 1994;33:49-63.

54. Zucker DK, Austin F, Fair A, Branchey L. Associations between patient religiosity and alcohol attitudes and knowledge in an alcohol treatment program. International Journal of the Addictions 1987;22:47-53.

55. Veach TL, Chappel JN. Measuring spiritual health: A preliminary study. Substance Abuse 1992;13:139-147.

56. Koenig HG, George LK, Cohen HJ, Hays JC, Blazer DG, Larson DB. The relationship between religious activities and cigarette smoking in older adults. Journal of Gerontology 1998;53A:M426-M434.

57. Office on Smoking and Health. Reducing the health consequences of smoking: 25 years of progress. A report of the surgeon general. DHHS publication No. (CDC) 89-8411. Washington, DC: U.S. Department of Health and Human Services, 1989.

58. Stark R. Religion as context: Hellfire and delinquency one more time. Sociology of Religion 1996;57:163-173.

59. Benson PL, Donahue MJ. Ten-year trends in at-risk behaviors: A national study of black adolescents. Journal of Adolescent Research 1989;4:125-139.

60. Rhodes AL, Reiss AJ. The "religious factor" and delinquent behavior. Journal of Research in Crime \& Delinquency 1970;7:83-98.

61. Wallace JM, Forman TA. Religion's role in promoting health and reducing the risk among American youth. Health Education \& Behavior 1998;25:721-741.

Direct reprint requests to:

Harold G. Koenig, M.D.

Box 3400

Duke University Medical Center

Durham, NC 27710 